\title{
PANGAN FUNGSIONAL UNTUK PROYEK INDEPENDEN KKN-TEMATIK DI MASA PANDEMI COVID-19
}

\author{
Nova Kurnia'1), Muhali'1), Hunaepi ${ }^{2)}$, Muhammad Asy'ari ${ }^{3)}$ \\ 1)Program Studi Pendidikan kimia, FSTT, Universitas Pendidikan Mandalika, Mataram, NTB, Indonesia \\ 2) Program Studi Pendidikan Biologi, FSTT, Universitas Pendidikan Mandalika, Mataram, NTB, Indonesia \\ ${ }^{3)}$ Program Studi Pendidikan Olahraga dan Kesehatan, FIKKM Universitas Pendidikan Mandalika, Mataram, NTB, \\ Indonesia \\ Corresponding author : hunepi \\ E-mail : hunaepi@undikma.ac.id
}

Diterima 06 November 2021, Direvisi 17 November 2021, Disetujui 18 November 2021

\begin{abstract}
ABSTRAK
Pandemi covid-19 telah membuat manusia banyak menderita penyakit hingga meninggal dunia di berbagai belahan dunia. Konsumsi pangan fungsional dapat memberikan manfaat kesehatan fisiologis dalam melawan dan terlindungi dari covid-19. Tujuan dari kegiatan pengabdian kepada masyarakat ini adalah mengenalkan pangan fungsional untuk proyek independen $\mathrm{KKN}-\mathrm{Tematik}$ dalam program Merdeka Belajar Kampus Merdeka (MBKM). Melalui kegiatan proyek independen, mahasiswa dapat merancang pangan fungsional berbasis potensi desa sebagai produk akhir inovatifnya. Kegiatan pengabdian kepada masyarakat berlangsung pada tanggal 9 dan 16 September 2021 secara luring dan daring dengan menggunakan metode knowledge rasfer dan Community development. Kegiatan ini terdiri dari tahapan persiapan, pelaksanaan, dan evaluasi. Evaluasi kegiatan dilakukan menggunakan rubrik penilaian tugas dan angket persepsi mahasiswa. Hasil kegiatan pengabdian kepada masyarakat menunjukkan bahwa 1) mahasiswa telah mampu memetakan potensi sumber daya alam desa; 2) mahasiswa sudah memahami konsep senyawa bioaktif; dan 3) mahasiswa dapat menggunakan referensi ilmiah sebagai dasar proyek. Tanggapan mahasiswa terhadap kegiatan pengabdian kepada masyarakat sangat positif.
\end{abstract}

Kata kunci: pangan fungsional; proyek independen; KKN; pandemi covid 19

\begin{abstract}
The COVID-19 pandemic has caused many people to suffer from diseases and die in various parts of the world. Consumption of functional foods can provide physiological health benefits in fighting and protecting against COVID-19. The purpose of this community service activity is to introduce functional food for the Thematic-KKN independent project in the Merdeka Learning Campus Merdeka (MBKM) program. Through independent project activities, students can design functional food based on village potential as an innovative final product. Community service activities take place on 9 and 16 September 2021 offline and online using the knowledge transfer and community development methods. This activity consists of the preparation, implementation, and evaluation stages. Evaluation of activities was carried out using the assignment assessment rubric and student perception questionnaires. The results of community service activities show that 1 ) students have been able to map the potential of village natural resources; 2) students already understand the concept of bioactive compounds; and 3) students can use scientific references as the basis for the project. Student responses to community service activities were very positive.
\end{abstract}

Keywords: functional food; independent project; community service program; covid 19 pandemic

\section{PENDAHULUAN}

Kebijakan Merdeka Belajar-Kampus Merdeka (MBKM) dari Kementerian Pendidikan Kebudayan dan Pendidikan Tinggi memberikan hak kepada mahasiswa untuk 3 semester belajar di luar program studinya. Kebijakan MBKM memberikan tantangan dan kesempatan kepada mahasiswa untuk pengembangan inovasi, kreativitas, kapasitas, kepribadian dan mengembangkan kemandirian. Bentuk kegiatan pembelajaran yang dapat diambil oleh mahasiswa berupa kegiatan magang di industri, membangun desa, mengajar di sekolah, pertukaran mahasiswa, penelitian di lembaga riset, pengembangan kewirausahaan, proyek mandiri, dan proyek kemanusiaan(Kementrian Pendidikan dan Kebudayaan, 2020). Mahasiswa melalui program MBKB diberikan kesempatan seluas-luasnya untuk mengembangkan dirinya dengan segala 
potensi yang dimiliki baik pengetahuan, keterampilan, maupun sikap dalam wujud yang kreatif dan inovatif.

Program Studi Pendidikan Kimia Universitas Pendidikan Mandalika menjalankan kebijakan MBKM dalam berbagai bentuk kegiatan. Salah satu kegiatan MBKM yang dijalankan yaitu proyek independen yang dilakukan bersamaan dengan kegiatan Kuliah Kerja Nyata Tematik (KKN-Tematik) bagi mahasiswa semester VII (Khery et al., 2021). Proyek independen bagi mahasiswa bertujuan untuk mewujudkan gagasan dalam mengembangkan produk inovatif, menyelenggarakan pendidikan berbasis riset dan pengembangan (R\&D), meningkatkan partisipasi dalam penerapan inovasi bagi masyarakat dan meningkatkan prestasi di ajang nasional dan internasional (Kementrian Pendidikan dan Kebudayaan, 2020). Melalui kegiatan ini mahasiswa dapat melaksanakan pengimplementasian gagasan pengetahuan dalam mengembangkan produk inovatif bagi masyarakat sesuai potensi yang dimiliki sebagai upaya penyelenggaraan kegiatan pendidikan berbasis $R \& D$.

Proyek independen KKN-Tematik dapat ditempuh oleh mahasiswa salah satunya melalui mata kuliah Kimia Bahan Makanan dan Zat Aditif. Sasaran proyek independen KKNTematik tahun 2021 adalah menghasilkan produk pangan sehat berbasis potensi desa di masa pandemi covid-19. Hingga Agustus 2021, total kasus positif covid-19 di Indonesia yang terkonfirmasi sebanyak 4.073.831 kasus, jumlah kasus sembuh sebanyak 3.724.318 kasus, dan jumlah kasus meninggal sebanyak 131.923 kasus (Satgas Covid 19, n.d.). Selain pandemi covid-19, bahaya serius lainnya yaitu meningkatnya prevalensi penyakit tidak menular antara lain diabetes melitus, kanker, penyakit paru, obesitas, dan penyakit jantung (Kemenkes RI, 2020). Oleh karena itu upaya peningkatan kesehatan dan pencegahan penyakit perlu digalakkan secara berkelanjutan melalui konsumsi pangan sehat.

Pangan sehat yang akan dibuat melalui proyek independen KKN-Tematik nantinya yaitu pangan fungsional. Pangan fungsional dapat didefinisikan sebagai pangan baik segar maupun olahan yang mengandung komponen bioaktif dan memberikan manfaat kesehatan fisiologis baik dalam mencegah atau menurunkan resiko penyakit, meningkatkan kesehatan, maupun merawat kesehatan yang dikonsumsi dalam jumlah biasa (Hasler, 2002; Nicoletti, 2012). Komponen bioaktif merupakan senyawa kimia yang menjadi sumber manfaat kesehatan dari pangan fungsional, dapat berupa senyawa metabolit sekunder seperti senyawa polifenol, flavonoid, asam fenolat, serat, dan beberapa peptida (Jiang et al., 2020; Macagnan et al., 2016). Pemahaman pangan sehat (pangan fungsional) dan komponen bioaktif bagi mahasiswa sangat penting dalam menunjang pelaksanaan kegiatan KKNTematik karena berhubungan langsung dengan masyarakat di era pandemi Covid-19 saat ini.

Biodiversitas Indonesia merupakan sumber komponen bioaktif yang sangat melimpah bagi pengembangan pangan fungsional dalam berbagai manfaat kesehatan (Andarwulan et al., 2012). Berbagai olahan pangan fungsional berbasis sumber daya alam lokal Indonesia telah banyak dikembangkan antara lain beras analog dari bekatul bagi penderita diabetes (Noviasari et al., 2015), kue minyak sawit merah tinggi antioksidan (Harianti et al., 2018), hingga jelly dari daun hantap yang kaya antioksidan (Pamungkas et al., 2014). Oleh karena itu, kegiatan pengabdian kepada masyarakat ini ditujukan untuk mengenalkan pangan fungsional sebagai produk akhir proyek independen KKN-Tematik yang akan dikembangkan oleh mahasiswa terutama dalam fokus senyawa bioaktif

\section{METODE}

Metode dalam pengabdian kepada masyarakat dilaksanakan dengan metode knowledge rasfer dan Community development yaitu pendekatan yang melibatkan mitra secara langsung sebagai obyek dan subyek dalam pelaksanaan kegiatan pengabdian kepada masyarakat

Kegiatan pengenalan pangan fungsional berlangsung dalam dua sesi yaitu pada tanggal 9 dan 16 September 2021. Teknis kegiatan pengenalan ini dilakukan secara luring dan daring. Pelaksanaan secara daring melalui google meet dilakukan bagi mahasiswa yang masih berada di kampung halamannya di luar Pulau Lombok dan belum memungkinkan kembali ke kampus secepatnya akibat pandemi covid-19. Sementara itu, pelaksanaan secara luring diperuntukan bagi mahasiswa yang berada di Pulau Lombok dan dapat masuk ke kampus Universitas Pendidikan Mandalika. Peserta kegiatan pengenalan pangan fungsional yaitu 22 orang mahasiswa pendidikan kimia Universitas Pendidikan Mandalika yang memprogramkan mata kuliah Kimia Bahan Makanan dan Zat Aditif.

Kegiatan pengenalan pangan fungsional ini dilakukan dalam beberapa tahap yaitu:

1) Tahap Persiapan

Tahap persiapan dilakukan dengan penyusunan berbagai jenis kelengkapan kegiatan pengenalan pangan fungsional di antaranya sebagai berikut. 
a. Materi pengenalan proyek independen KKN-Tematik

b. Rubrik penilaian tugas yang dikerjakan mahasiswa.

Rubrik penilaian untuk membantu Tim Pengabdian dalam menilai dan mengetahui pemahaman mahasiswa terkait pangan fungsional khususnya sumber daya alam lokal desa setempat beserta kandungan senyawa bioaktifnya. Rubrik penilaian yang disusun termasuk rubrik analitik dengan rentang skor 0 3 dan deskripsi tiap skor sebagaimana yang tercantum pada Tabel 1(Kurnia et al., 2020) di bawah ini.

Tabel 1. Rubrik penilaian penugasan pengenalan pangan fungsional

\begin{tabular}{|c|c|c|}
\hline $\begin{array}{r}\text { Aspek } \\
\text { yang dinilai }\end{array}$ & Indiktor & Skor \\
\hline \multirow{4}{*}{$\begin{array}{l}\text { Kemampuan } \\
\text { pemetaan } \\
\text { pangan lokal }\end{array}$} & Tidak mendata & 0 \\
\hline & $\begin{array}{l}\text { Hanya mendata } 1 \\
\text { jenis bahan pangan } \\
\text { lokal }\end{array}$ & 2 \\
\hline & $\begin{array}{l}\text { Mendata } 2-3 \text { jenis } \\
\text { bahan pangan lokal }\end{array}$ & 3 \\
\hline & $\begin{array}{l}\text { Mendata } 4 \text { atau lebih } \\
\text { bahan pangan lokal }\end{array}$ & 4 \\
\hline \multirow{4}{*}{$\begin{array}{l}\text { Pemahaman } \\
\text { senyawa } \\
\text { bioaktif yang } \\
\text { terkandung } \\
\text { dalam bahan } \\
\text { pangan lokal } \\
\text { desa }\end{array}$} & $\begin{array}{l}\text { Tidak } \\
\text { mencantumkan } \\
\text { senyawa bioaktif dari } \\
\text { bahan pangan lokal }\end{array}$ & 0 \\
\hline & $\begin{array}{l}\text { Mencantumkan } \\
\text { senyawa bioaktif dari } \\
\text { bahan pangan lokal } \\
\text { dengan tidak } \\
\text { lengkap dan tepat }\end{array}$ & 2 \\
\hline & $\begin{array}{l}\text { Memahami senyawa } \\
\text { bioaktif dari bahan } \\
\text { pangan lokal dengan } \\
\text { cukup lengkap dan } \\
\text { tepat }\end{array}$ & 3 \\
\hline & $\begin{array}{l}\text { Memahami senyawa } \\
\text { bioaktif dari bahan } \\
\text { pangan lokal secara } \\
\text { lengkap dan tepat }\end{array}$ & 4 \\
\hline \multirow{4}{*}{$\begin{array}{l}\text { Referensi } \\
\text { yang menjadi } \\
\text { acuan }\end{array}$} & $\begin{array}{l}\text { Tidak ada referensi } \\
\text { sama sekali }\end{array}$ & 0 \\
\hline & $\begin{array}{l}\text { Tidak menggunakan } \\
\text { referensi dari jurnal } \\
\text { internasional } \\
\text { bereputasi/nasional } \\
\text { terakreditasi }\end{array}$ & 2 \\
\hline & $\begin{array}{l}\text { Sebagian } \\
\text { menggunakan } \\
\text { referensi dari jurnal } \\
\text { internasional } \\
\text { bereputasi/nasional } \\
\text { terakreditasi }\end{array}$ & 3 \\
\hline & $\begin{array}{l}\text { Secara keseluruhan } \\
\text { menggunakan } \\
\text { referensi dari jurnal }\end{array}$ & 4 \\
\hline
\end{tabular}

internasional bereputasi/nasional terakreditasi

c. Angket persepsi mahasiswa terhadap kegiatan pengenalan pangan fungsional.

Angket persepi dirancang untuk menjaring persepsi mahasiswa terhadap kegiatan pengenalan pangan fungsional. Skala Likert dengan lima opsi tanggapan (Sangat Setuju, Setuju, Netral, Tidak Setuju, dan Sangat Tidak Setuju) digunakan dalam angket ini (Miller et al., 2009). Angket persepsi terdiri atas 4 (empat) butir pernyataan positif yaitu (P1) Koherensi antara materi yang disampaikan dengan tema kegiatan pengenalan, (P2) Materi pengenalan pangan fungsional dapat diterima dengan mudah, (P3) Jawaban yang disampaikan oleh pemateri atas pertanyaan mahasiswa sangat jelas, dan (P4) Pasca kegiatan pengenalan, saya memahami bagaimana konsep produk akhir proyek independen KKN-Tematik.

2) Tahap Pelaksanaan

Tahap pelaksanaan yaitu penyampaian materi pengenalan pangan fungsional oleh tim pengabdian masyarakat. Penyampaian dilakukan baik secara daring maupun luring dan materi dibagikan kepada mahasiswa.

3) Tahap Evaluasi

Tahap evaluasi dilakukan setelah kegiatan pengenalan selesai dilakukan dengan memberikan suatu penugasan dalam bentuk penyusunan laporan akhir. Laporan akhir penugasan dikumpulkan setelah mahasiswa proyek mandiri KKNTematik menyelesaikan tahapan observasi lapangan hingga hari ke-7. Tugas dikumpulkan melalui email atau whatsapp. Penilaian tugas yang dikerjakan oleh mahasiswa dilakukan menggunakan rubrik penilaian analitik yang telah disusun sebelumnya.

Teknik analisis data

1. Data rubrik penilaian penugasan

Teknik analisis data penugasan mahasiswa dengan menjumlahkan skor tiap komponen dan dibagi dengan skor maksimum, kemudian dikalikan dengan nilai persentase sebagaimana persamaan 1 .

$S A=\frac{S P}{S M} \times 100 \%$

Keterangan :

SA : skor akhir

SP : skor yang diperoleh (jumlah keseluruhan dari skor tiap komponen penilaian) SM : skor maksimum

Data yang diperoleh, selanjutnya diinterpretasi menggunakan pedoman kriteria 
interpretasi yang tercantum pada Tabel 2 di bawah ini.

Tabel 2. Pedoman kriteria interpretasi skor rubrik penugasan

\begin{tabular}{cl}
\hline $\begin{array}{c}\text { Nilai persen } \\
(\%)\end{array}$ & \multicolumn{1}{c}{ Kategori } \\
\hline $81-100$ & Sangat tinggi \\
$61-80$ & Tinggi \\
$41-60$ & Sedang \\
$21-40$ & Rendah \\
$0-20$ & Sangat rendah \\
\hline
\end{tabular}

\section{Data angket}

Angket persepsi mahasiswa

menggunakan lima opsi tanggapan/jawaban yaitu Sangat Setuju (skor 5), Setuju (skor 4), Netral (skor 3), Tidak Setuju (skor 2), dan Sangat Tidak Setuju (skor 1) (Miller et al., 2009). Data persepsi yang telah terkumpul kemudian ditabulasi berdasarkan pilihan persepsi masingmasing mahasiswa.

\section{HASIL DAN PEMBAHASAN}

Mata kuliah Kimia Bahan Makanan dan Zat Aditif dalam struktur kurikulum Merdeka Belajar-Kampus Merdeka (MBKM) dari Program Studi Pendidikan Kimia Universitas Pendidikan Mandalika, dapat ditempuh melalui kegiatan proyek independen KKN-Tematik (Khery et al., 2021). Kegiatan pengenalan pangan fungsional menjadi sumber pengetahuan baru bagi mahasiswa yang melaksanakan proyek independen KKNTematik untuk merancang produk akhir berbasis potensi desa setempat.

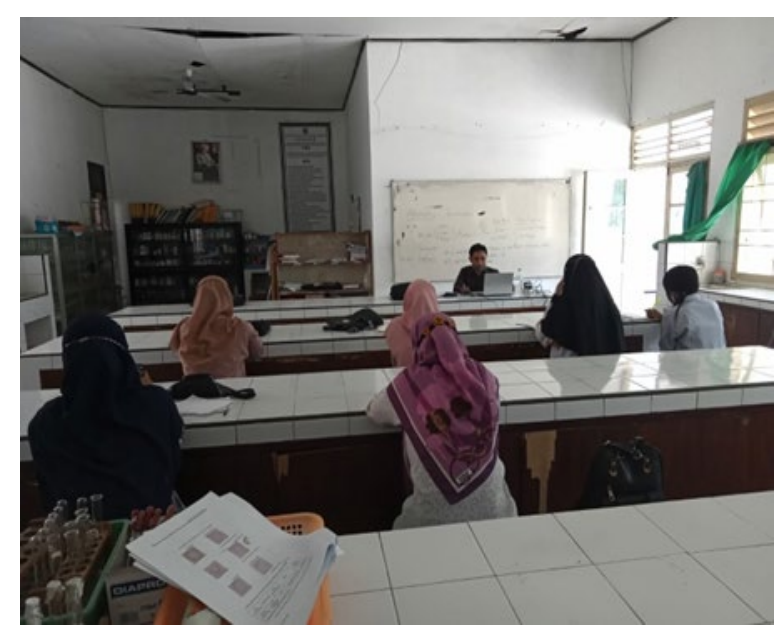

Gambar 1. Kegiatan pengenalan pangan fungsional untuk proyek independen KKN-Tematik

Materi pengenalan antara lain meliputi konsep umum kimia pangan, sejarah dan konsep dasar pangan fungsional, bioavabilitas senyawa bioaktif dan teknik perancangan pangan fungsional beserta contoh praktis yang telah dilakukan peneliti lain (Gambar 2).

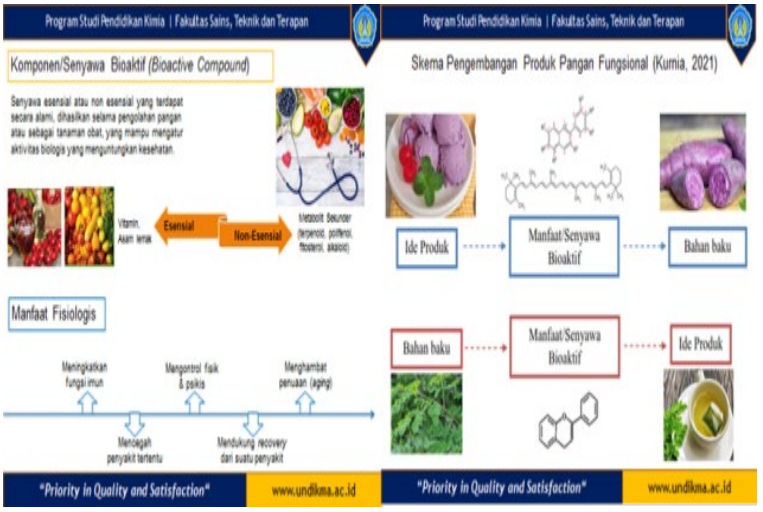

Gambar 2. Materi pengenalan pangan fungsional untuk proyek independen $\mathrm{KKN}$-Tematik

Pengetahuan mahasiswa terkait pangan fungsional berbasis potensi desa dapat dilihat dengan memberikan penugasan mandiri. Penugasan mandiri terkait pangan fungsional dibatasi hanya pada langkah awal dari pengembangan suatu produk pangan fungsional. Batasan tersebut berupa pemetaan bahan pangan yang menjadi potensi desa, senyawa bioaktif yang terkandung di dalam bahan pangan dan referensi ilmiah yang menunjukkan senyawa bioaktif terdapat dalam bahan pangan tersebut. Oleh karena itu, penugasan mandiri ini dilakukan oleh mahasiswa dimulai sejak pelepasan kegiatan proyek independen KKN-Tematik hingga 7 (tujuh) hari lamanya. Hasil penugasan yang dilakukan oleh mahasiswa tersebut tersaji pada Gambar 3.

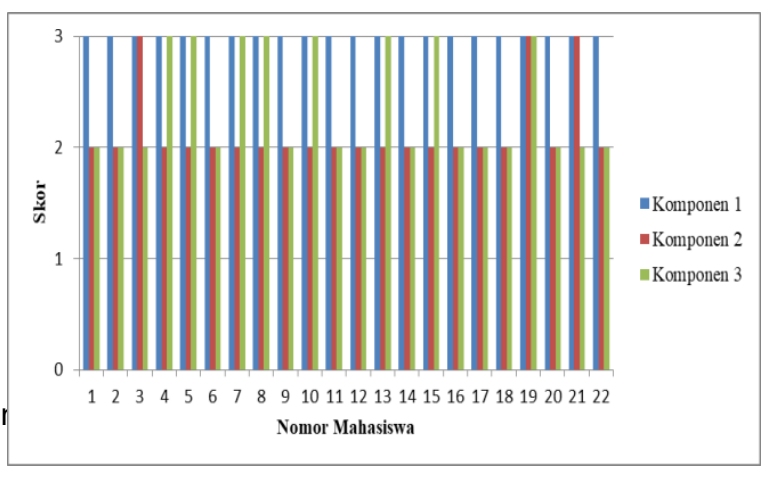


Gambar 3. Sebaran nilai penugasan yang dilakukan mahasiswa (Komponen 1 yaitu kemampuan pemetaan potensi desa, Komponen 2 yaitu pemahaman senyawa bioaktif, dan Komponen 3 yaitu referensi yang diacu)

\section{1) Kemampuan Pemetaan Potensi Desa}

Kemampuan pemetaan pangan lokal menjadi salah satu kemampuan yang harus dimiliki oleh mahasiswa KKN-Tematik secara baik. Hasil dari pemetaan potensi sumber daya desa ini mengarahkan mahasiswa kepada ide produk pangan fungsional yang akan dikembangkannya. Berdasarkan Gambar 3, kemampuan pemetaan potensi desa oleh mahasiswa KKN-Tematik sangat baik. Semua mahasiswa memperoleh skor tinggi (3) yaitu mampu mendata berbagai potensi desa tempat penyelenggaraan KKN-Tematik. Hasil ini sangat didukung dengan lokasi KKN-Tematik yang merupakan desa atau kecamatan tempat tinggal mahasiswa. Lokasi pelaksanaan proyek independen KKN-Tematik ini tersebar merata di dua pulau baik itu Pulau Lombok maupun Pulau Sumbawa, bahkan terdapat juga mahasiswa yang melaksanakan kegiatan proyek independen KKN-Tematik di Provinsi Nusa Tenggara Timur yang merupakan tempat tinggalnya.

2) Pemahaman Senyawa Bioaktif

Senyawa bioaktif menjadi bagian utama yang penting dikuasai dalam pengembangan suatau pangan fungsional. Senyawa bioaktif merupakan komponen ekstra gizi yang terdapat dalam jumlah yang kecil dalam suatu bahan pangan (Teodoro, 2019). Senyawa bioaktif menyediakan manfaat fisiologis yang akan dimiliki oleh suatu pangan fungsional untuk menunjang kesehatan manusia. Pemahaman mahasiswa yang baik tentang senyawa bioaktif sangat berpengaruh positif terhadap pangan fungsional yang dikembangkan (Kurnia et al., 2020). Selain itu, dengan mengetahui senyawa bioaktif yang terkandung dalam suatu bahan pangan dapat menjadi pertimbangan dalam penentuan teknik pengolahan. Hal tersebut mengingat sensitivitas dari senyawa bioaktif terhadap proses pengolahan (Knorr \& Watzke, 2019).

Data menunjukkan bahwa mayoritas pemahaman mahasiswa terkait senyawa bioaktif dalam kategori medium dengan skor 2 yaitu mampu memahami senyawa bioaktif dari bahan pangan lokal dengan cukup lengkap dan tepat. Hanya 3 orang mahasiswa saja yang mampu memperoleh skor tinggi (skor 3). Meskipun demikian, tidak terdapat mahasiswa yang tidak mampu memahami senyawa bioaktif atau yang memperoleh skor 1 maupun 0 . Sekitar 1-2 orang mahasiswa masih mengalami miskonsepsi terkait konsep senyawa bioaktif. Sebagai contoh, mahasiswa masih menuliskan istilah seperti antioksidan atau antiinflamasi sebagai senyawa bioaktif dalam suatu bahan pangan, padahal antioksidan atau antiinflamasi lebih tepatnya merupakan suatu fungsi atau manfaat yang dimiliki oleh senyawa bioaktif tertentu seperti kebanyakan golongan flavonoid (Maleki et al., 2019; Panche et al., 2016).

3) Referensi yang digunakan

Referensi yang baik dapat menguatkan dan mendukung penelitian yang dilakukan seorang peneliti (Santini, 2018). Ihwal pengembangan pangan fungsional dalam KKNTematik ini, referensi yang diacu oleh mahasiswa juga menjadi pijakan utama. Hal ini dilakukan agar klaim terhadap manfaat kesehatan dari bahan pangan dapat terjamin keilmiahannya. Selain itu untuk mendorong para mahasiswa agar terbiasa mengerjakan atau menulis sesuatu berbasis data sehingga kualitas tulisan atau karyanya tinggi (Kurnia et al., 2020).

Berdasarkan hasil penugasan yang telah dilakukan, mayoritas mahasiswa telah mampu menyajikan referensi dengan kualitas yang baik seperti jurnal internasional bereputasi, jurnal nasional terakreditasi, laporan tugas akhir dalam bentuk tesis dan disertasi, dan majalah ilmiah nasional. Artikel-artikel ilmiah dalam jurnal bereputasi baik internasional maupun nasional telah melalui proses telaah dan peninjauan oleh tim review yang memang ahli di bidangnya. Hal ini tentu memberikan kualitas tinggi artikel tersebut sebagai sumber yang akurat dan terpercaya (Feinstein, 2008).

Data skor akhir yang diperoleh mahasiswa setelah dilakukan pengolahan menggunakan persamaan 1 seperti disajikan pada Gambar 4 sebagai berikut.

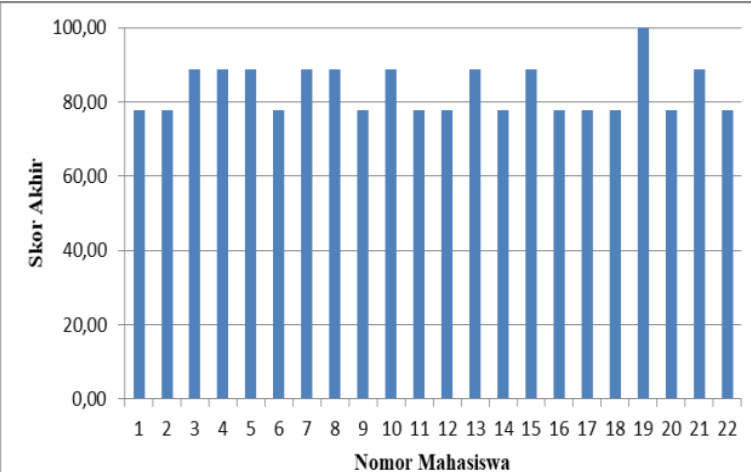


Gambar 4. Skor akhir hasil penugasan mahasiswa

Berdasarkan Gambar 4, terlihat bahwa skor akhir yang diperoleh dalam kategori tinggi (61$80 \%$ ) sebanyak 12 orang mahasiswa dan kategori sangat tinggi $(81-100 \%)$ sebanyak 10 orang mahasiswa. Oleh karena itu, dapat disimpulkan bahwa pengetahuan mahasiswa terkait pangan fungsional setelah adanya program pengenalan sangat baik. Hasil ini sejalan dengan temuan (Kusmiyati et al., 2021) yang menunjukkan adanya pengaruh positif edukasi yang diberikan dalam bentuk penyuluhan terkait usaha perbaikan gizi keluarga (UPGK) melalui pemanfaatan pekarangan rumah di masa pandemi covid-19.

Pemahaman mahasiswa yang baik terkait strategi perancangan pangan fungsional juga didukung oleh data persepsi mahasiswa (Gambar 5). Terdapat 4 pernyataan positif yang menjadi butir pernyataan angket.

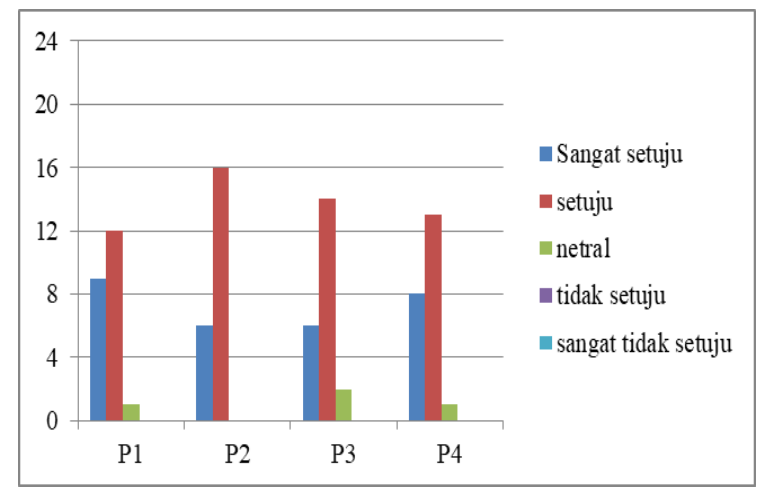

Gambar 5 Grafik Persepsi mahasiswa tentang pangan fungsional

Keterangan :

P1 : Kesesuaian antara materi yang disampaikan dengan tema kegiatan pengenalan.

P2 : Materi pengenalan pangan fungsional dapat diterima dengan mudah.

P3 : Jawaban yang disampaikan oleh pemateri atas pertanyaan mahasiswa sangat jelas dan dapat diterima.

P4 : Setelah mengikuti kegiatan pengenalan, saya memahami bagaimana konsep produk akhir proyek independen KKN-Tematik yang akan saya kerjakan.

Secara umum, tanggapan mahasiswa terhadap kegiatan pengenalan pangan fungsional ini tergolong baik. Setiap butir pernyataan didominasi oleh tanggapan sangat setuju dan setuju. Sebagai contoh, butir pernyataan pertama terkait koherensi antara materi yang disampaikan dengan tema pengenalan memiliki tanggapan sangat setuju sejumlah 9 orang, setuju 12 orang dan netral 1 orang. Koherensi menjadi salah satu prinsip utama yang harus diperhatikan dalam setiap pengembangan perangkat pembelajaran bahkan kurikulum karena sangat mendukung peningkatan hasil pembelajaran mahasiswa (Canrinus et al., 2017; Foster et al., 2021).

\section{SIMPULAN DAN SARAN}

Kegiatan pengabdian kepada masyarakat ini mampu memberikan pemahaman yang baik kepada mahasiswa tentang pangan fungsional (senyawa bioaktif) berbasis potensi desa sebagai produk akhir dari proyek independen KKN-Tematik di masa pandemi covid-19. Mahasiswa juga memberikan persepsi yang sangat baik terhadap kegiatan pengabdian kepada masyarakat.

\section{UCAPAN TERIMAKASIH}

Kegiatan PkM ini dapat terlaksana karena dukungan dari Fakultas Sains, Teknik, dan Terapan (FSTT) Universitas Pendidikan Mandalika, Lembaga Penelitian dan Pengabdian kepada Masyarakat (LPPM) Universitas Pendidikan Mandalika, dan Laboratorium Kimia FSTT Universitas Pendidikan Mandalika.

\section{DAFTAR RUJUKAN}

Andarwulan, N., Kurniasih, D., Apriady, R. A., Rahmat, H., Roto, A. V., \& Bolling, B. W. (2012). Polyphenols, carotenoids, and ascorbic acid in underutilized medicinal vegetables. Journal of Functional Foods, $4(1)$, 339-347. https://doi.org/10.1016/j.jff.2012.01.003

Canrinus, E. T., Bergem, O. K., Klette, K., \& Hammerness, K. (2017). Coherent teacher education programmes: Taking a student perspective. Journal of Curriculum Studies, 49(3), 313-333. https://doi.org/10.1080/00220272.2015.1 124145

Feinstein, J. (2008). The Importance of Accurate References in Journals. Editors' Bulletin, 4(3), 100-102. https://doi.org/10.1080/17521740802651 237

Foster, C., Francome, T., Hewitt, D., \& Shore, C. (2021). Principles for the design of a fullyresourced, coherent, research-informed school mathematics curriculum. Journal 
of Curriculum Studies, 53(5), 621-641. https://doi.org/10.1080/00220272.2021.1 902569

Harianti, R., Marliyati, S. A., Rimbawan, R., \& Sukandar, D. (2018). Development of High Antioxidant Red Palm Oil Cake as a Potential Functional Food. Jurnal Gizi Dan Pangan, 13(2), 63-70. https://doi.org/10.25182/jgp.2018.13.2.6 3-70

Hasler, C. M. (2002). Functional Foods: Benefits, Concerns and Challenges-A Position Paper from the American Council on Science and Health. The Journal of Nutrition, 132(12), 3772-3781. https://doi.org/10.1093/jn/132.12.3772

Jiang, L.-L., Gong, X., Ji, M.-Y., Wang, C.-C., Wang, J.-H., \& Li, M.-H. (2020). Bioactive Compounds from Plant-Based Functional Foods: A Promising Choice for the Prevention and Management of Hyperuricemia. Foods, 9(8), 973. https://doi.org/10.3390/foods9080973

Kemenkes RI. (2020). Keputusan Menteri Kesehatan Republik Indonesia Nomor HK.01.07/MENKES/328/2020—Protokol. Covid19.Go.Id.

https://covid19.go.id/p/protokol/panduanpencegahan-dan-pengendalian-coronavirus-disease-2019-covid-19-di-tempatkerja-perkantoran-dan-industri-dalammendukung-keberlangsungan-usahapada-situasi-pandemi

Kementrian Pendidikan dan Kebudayaan. (2020). Buku Panduan Merdeka Belajar: Kampus Merdeka - Direktorat Jenderal Pendidikan Tinggi Kementerian Pendidikan dan Kebudayaan Republik Indonesia.

https://dikti.kemdikbud.go.id/pengumum an/buku-panduan-merdeka-belajarkampus-merdeka/

Khery, Y., Dewi, A. D., \& Bilad, M. R. (2021). Pedoman kurikulum MBKM program studi pendidikan kimia. Program Studi Pendidikan Kimia Universitas Pendidikan Mandalika.

Knorr, D., \& Watzke, H. (2019). Food Processing at a Crossroad. Frontiers in Nutrition, $6, \quad 85$. https://doi.org/10.3389/fnut.2019.00085

Kurnia, N., Liliasari, Supriyanti, F. M. T., \& Adawiyah, D. R. (2020). Functional food project: A new and enjoyable topic in a food chemistry course. Journal of Physics: Conference Series, 1440, 012010. https://doi.org/10.1088/17426596/1440/1/012010

Kusmiyati, K., Rasmi, D. A. C., Khairuddin, K., Sedijani, P., \& Handayani, B. S. (2021).
Volume 5, Nomor 1, Desember 2021. p-ISSN : 2614-5251 e-ISSN : 2614-526X

Penyuluhan Tentang Usaha Perbaikan Gizi Keluarga (UPGK) Melalui Pemanfaatan Pekarangan dimasa Pandemi Covid 19. Jurnal Pengabdian Magister Pendidikan IPA, 4(3). https://doi.org/10.29303/jpmpi.v4i3.967

Macagnan, F. T., da Silva, L. P., \& Hecktheuer, L. H. (2016). Dietary fibre: The scientific search for an ideal definition and methodology of analysis, and its physiological importance as a carrier of bioactive compounds. Food Research International, $\quad 85, \quad 144-154$. https://doi.org/10.1016/j.foodres.2016.04 .032

Maleki, S. J., Crespo, J. F., \& Cabanillas, B. (2019). Anti-inflammatory effects of flavonoids. Food Chemistry, 299, 125124. https://doi.org/10.1016/j.foodchem.2019. 125124

Miller, M. D., Linn, R. L., Gronlund, N. E., \& Linn, R. L. (2009). Measurement and assessment in teaching (10th ed). Merrill/Pearson.

Nicoletti, M. (2012). Nutraceuticals and botanicals: Overview and perspectives. International Journal of Food Sciences and Nutrition, 63(sup1), 2-6. https://doi.org/10.3109/09637486.2011.6 28012

Noviasari, S., Kusnandar, F., Setiyono, A., \& Budijanto, S. (2015). BERAS ANALOG SEBAGAI PANGAN FUNGSIONAL DENGAN INDEKS GLIKEMIK RENDAH. Jurnal Gizi Dan Pangan, 10(3), Article 3. https://doi.org/10.25182/jgp.2015.10.3.\% $p$

Pamungkas, A., Sulaeman, A., \& Roosita, K. (2014). PENGEMBANGAN PRODUK MINUMAN JELI EKSTRAK DAUN HANTAP (Sterculia oblongata R. Brown) SEBAGAI ALTERNATIF PANGAN FUNGSIONAL. Jurnal Gizi Dan Pangan, 9(3), Article 3. https://doi.org/10.25182/jgp.2014.9.3.\%p

Panche, A. N., Diwan, A. D., \& Chandra, S. R. (2016). Flavonoids: An overview. Journal of Nutritional Science, 5. https://doi.org/10.1017/jns.2016.41

Santini, A. (2018). The Importance of Referencing. The Journal of Critical Care Medicine, 4(1), 3-4. https://doi.org/10.2478/jccm-2018-0002

Satgas Covid 19. (n.d.). Analisis Data COVID19 Indonesia (Update Per 29 Agustus 2021)—Berita Terkini | Covid19.go.id. Retrieved 7 November 2021, from https://covid19.go.id/p/berita/analisisdata-covid-19-indonesia-update-29agustus-2021 
Teodoro, A. J. (2019). Bioactive Compounds of Food: Their Role in the Prevention and Treatment of Diseases. Oxidative Medicine and Cellular Longevity, 2019, e3765986.

https://doi.org/10.1155/2019/3765986 